\title{
Case Study on the Influence of Chinese Traditional Philosophy to the Enterprise Management
}

\author{
Ning He \\ School of Economics and management, Xi'an Institute of Post \& Telecoms \\ 536 South of Chang'An Road, Xi'an, 710061, China \\ Tel: +86-133-9928-0905Ｅ-mail: hening915@126.com
}

Received: June 29, 2011 Accepted: July 26, 2011 doi:10.5430/jms.v2n3p73

\begin{abstract}
In today's uncertain business world, it is becoming difficult using the traditional strategy planning tools with the "design" thinking, the success of an enterprise is reliant on more flexible and rapid response to external changes. In order to survive or excel, the firms today have to change and adopt new management techniques. With Confucian principles once again openly thriving in China, the Chinese's traditional philosophy applies a constructivism perspective, coping with complexity and uncertainty by means of a clear methodological guideline and roadmap for both scholars and practitioners. The key idea of Confucianism is to achieve strategic alignment, for instance, the alignment between organizational strategy and individuals' behavior. This kind alignment embodies the final harmony in organization, including the fit between people and people, the fit between people and work, and the fit between business strategy and environment. (Youmin Xi, Xuanwei Cao, Liuxu Xiangli, 2010). This paper analyzes the success cases of NTT DoCoMo and Silicon organizations to show how the Confucian principles are penetrating into cultural circles of organization. As a core idea in the eastern culture, harmony has been developed into a special mentality, indicating a good relationship which the business organizations have to build with the environment. The purpose of this research is to provide some eastern perspectives to the classical management literatures.
\end{abstract}

Keywords: Social network, Inter-firm research, Coopetition, Chinese Confucianism

\section{Introduction}

Today's rapid dynamic business environment forces all organizations to struggle between the battle for survival and the battle for excellence. Obviously, management itself is a highly cultural activity, so this paper applies the cross culture method to carry a case study of NTT DoCoMo and Silicon organizations to explore the secretes of firm's success.

Comparatively, the framework of Western and Eastern work ethic studies is totally different, the differences and similarities are resulted from the different origins and core components of both systems. The similarities are that both promote thrift, hard work, and sense of shame. Confucianism highlights humanity, righteousness, proprieties, wisdom, trust, harmony, loyalty, the family life and personality development; whereas the western principle underscores that the individual should take responsibility. Confucianism is an Oriental heritage, the mechanism of this cultural gene is to control the behavior of people who are born and raised under Confucian cultural influence. This Confucian culture is the unique nucleus of the behavior in East Asia, like Christianity is essential for people's behavior in the West (Thomas Hosuck Kang, 1997).

Confucius is not just a character belongs to individuals; it also has a very profound influence to management activities of modern enterprises. Besides, Confucianism not only affects Chinese people's thinking, but also belongs to the global citizens. Many scholars abroad have been studying Confucianism with the expectation of finding some universal values for the whole world. This paper aims to analyze how the Chinese traditional philosophy can enrich the western classical management principles, especially in the business arena with high uncertainty.

Concerning methodology, note that this paper does not follow a standard research approach (empirical modeling), but builds on insights from existing literatures. Opinions were collected from the media and other primary sources. The $\mathrm{ABI} /$ Inform database was widely used. With regard to the contribution of this thesis, the article aims at contributing to the theoretical and practical policy discussions in two ways. At a conceptual level, it proposes an innovative framework for the existed classical management literatures by introducing the old Chinese philosophy principles. At a practical level, the article aims at helping the firm leaders to solve complicated, uncertain management issues arising from today's dynamic business areas. Therefore, from the perspective of Chinese philosophy, the modern management activities 
based on mature western methods and tools should be largely modified and adjusted with the rapid development and changes of current enterprises.

\section{2. "Human element" in stead of "system element" to business success}

In traditional west management, scientific research methods such as optimizing, operation research, and algorithm are usually applied to solve complex problems, while cultural, psychological, and behavior aspects of human behavior are less considered. In contrast, Chinese classical philosophy explores the intrinsic power of human beings in order to cope with unpredicted things and emerging complexity. Obviously, it is significant to go beyond the purely technological issue of a firm's strategy, and to combine it with the social aspects, especially when firms and customers tend to communicate much more than in the past. It shows that psychological and sociological network effects become an important component of business success, for social networks can reinforce a firm's past successes or failures.

In practice, Participating in inter-firm research has become popular to enhance corporate entrepreneurship. At the same time, in the existing literature there is also a consensus that cooperation is the prevailing and vital behavior for these firms. Under such a circumstances, the network approach is to provide an explanatory framework of inter-firm research and to encourage both cooperation and competition, which can be described as a hybrid level of inter-firm relationship between pure cooperation and pure competition, named as "coopetition”(Aihie Osarenkhoe , 2010). Obviously, Coopetition refers to the situation when competitors have both a competitive and a cooperative relationship with each other simultaneously. Numerous empirical findings demonstrate that organizations can thrive by cooperating and competing, the reason is simple: cooperation helps create a bigger pie so a business can win a bigger piece of the pie through competition.

In order to achieve common goals, Successful cooperation should be based on trust and high commitment. For the well-functioning social networks, Trust, relationship diversity and knowledge transfer, and corporate entrepreneurship are considered some of the prominent cornerstones. In the "coopetition" era, the "human element" plays a more significant role than the "system element". In stead of discussing the "hard" issues in the supply chain, the "soft" issues of trust and learning should been given sufficient scholarly attention in this uncertain age.

\section{Case study}

\subsection{I-mode and DoCoMo's growth strategy}

Japan is an island country, poor in natural resources. As a symbol of the East Asian miracle, it got a rapid development after the World War II and leaped into the second largest economic power. Its unique management model is definitely worth learning by countries all over the world. From a historical perspective, it can be partly attributed to the spread of science and technology developed in Europe and the United States, but the primary reason is that Japan can make a good combination of science and technology on the one hand, and the Confucian philosophy on the other, creating a unique enterprise culture.

It's widely known that Confucian philosophy is generally regarded as the root of many Japanese's firm's cultural behaviors, which compassing a wide variety of concepts like the collectivistic social structure, respect for hierarchy and harmonious relationships. Every individual should keep harmonious relationships within the group and in order to maintain such harmonious relationship, respect for age and hierarchy is of great significance. Obviously, Japan is a country deeply affected by many traditional Chinese Confucian culture. For examples, Teamwork concepts play a dominant role in Japanese companies; Japan society does have so many races; a strong spirit of cooperation is the leading culture of Japanese corporations with a long family tradition; Japanese are group-oriented, high trust and less familiastic; the social-relationship of ruler-minister, father-son, husband-wife, elder-younger brother, and friend-friend are common in Japanese's firms.

In the Confucian culture, the concept of guanxi roots deeply in many aspects of Chinese peoples' lives. Trust built on guanxi is significantly stronger than contractual agreements made on the basis of impersonal laws and institutions. In Asian societies, this kink of guanxi-based trust is the touchstone of individual relationships which implies cultural confidence in the cooperation or social-cultural embeddedness. From above mentioned, Success in inter-firm relationship is built on skills of stakeholder relationship enhancement which needs a long-term strategic commitment to learning and trust. The success I-mode and DoCoMo's growth strategy can prove the role of traditional Chinese Confucian to Japanese’s firms. (Mitsuru Kodama, 2005)

In unpredictable, rapidly changing, ambiguous markets, Speed and flexibility are particularly essential when making decisions with external strategic partners. In Japan, 3rd-generation mobile communications service started in October 2001, making video communications via mobile phone provided by DoCoMo successful. A major feature of DoCoMo’s success is that the firm formed their social network very quickly. The decisive factor behind this rapid formation of 
social network is High levels of value resonance and embeddedness DoCoMo has with the partners. These variables describe the collaboration degree in inter-organizational relationships. Highly embedded collaborations makes the partners fulfill the network's mission and goals, share values in the business. DoCoMo did a great job to build deep interaction, to develop a strong mutual awareness and High levels of involvement in the collaborative process among community members.

Actually, the secretes of DoCoMo's success is that the combined synergy and dialectical leadership resulted in a very high level of synthesizing capability that enabled DoCoMo to form new business models quickly. Obviously, it's the task of DoCoMo's leader to build a platform for resonating values, to create relationships of mutual trust, to engage in establishing mutual exchanges, deep collaboration, high involvement and high embeddness at the boundaries of multiple partners. In conclusion, DoCoMo successfully conduct dialectical management based on dialectical leadership and engage in dialectical dialog to solve the various differences among the community leaders. From the above analysis, the Chinese classical philosophy did play a very significant role to this Japanese corporation's thriving.

\subsection{Driving forces of Silicon Valley's success}

In Silicon of the United States, there are lots of famous high-tech innovative firms. Research has proved that these firms's success is largely contributed to the effective social networks. It is because of a unique culture that made this 'Silicon Valley' model hard to copy by other countries. Just like the DoCoMo case, the Silicon Valley firms also relie on social networks to transmit information and produce innovation. Social networks work like a governance mechanism that Binds entrepreneur, inventors, and other institutional actors together into a coherent system.

For any firms, providing the right product at the right time is crucial for the survival and growth in a rapidly changing environment. Especially, for the high-tech industry, the feature of this industry is that: the knowledge base is complex, the sources of expertise are broadly dispersed, the locus of innovation lies in social networks rather than in individual firms, and the knowledge transferring play a very important role to the firm's innovative activities. Because innovation is so central to high-technology industry that it is not an exaggeration to say that effective social networks determine a firm's chance for survival. Interactions between entrepreneur, inventors, and other institutional actors weave a complex social network. This network of social relations penetrate irregularly in different sectors of Silicon Valley, and enable people to mobilize capital, find relevant and reliable information quickly. (Joseph Leu, 2006)

In Silicon Valley, many firms have strong ability to restructure itself by forming informal and virtual teams both inside and outside the company. In a very decentralized system, dense social networks and open labor markets encourage entrepreneurship and mobilization of resources. The great capability of Silicon Valley firms to accomplish this recombination of knowledge and capital contributed to the construction of dense social networks. Like the Japanese company DoCoMo , Silicon Valley firms have also build a very harmonious relationship with the external organizations, this relationship have characteristics of mutual trust, tight cooperation, value resonance, high involvement and embedness as well. In conclude, the above mentioned cases of DoCoMo and Silicon Valley firms shows how broad and profound the classical Chinese philosophy is to the business arena.

\section{Chinese philosophy's contribution to management}

With the fast development of enterprises management theory, It's clear that management activities themselves have great embeddedness and interactivity with human beings, and more and more uncertainty and complexity in enterprise operations should be finally traced back to the complexity of the human aspect. However current scholars are still confused about which approach should be used in the 21century business world.

In terms of the methodology for coping with uncertainty and complexity, reductionism-based philosophy is the core pillar of modern Western science, especially the mainstream branch of management science. With the renaissance of Confucian thinking in China in recent years, harmony is regarded as a universal principle and an ideal status in Confucian philosophy. In face of increasing uncertainty and complexity, the Eastern philosophical wisdom advocates to internalize the complexity of people rather than avoiding or reducing the uncertainty and complexity. Chinese culture's intelligence on tolerating and coping with ambiguity, uncertainty, and complexity shows a fact that maybe it would be an interesting research field to borrow Eastern philosophical intelligence for problem solving. It is correct to make a synthesis of Western and Eastern epistemology, and to combine the Western tradition, which emphasizes on experimentation and quantitative formulations, with a tradition such as the Chinese one, which encourages a spontaneous, self-organizing world together.

The more insightful research should be conduced to solve complex managerial problems in modern organizations in the face of uncertainty and turbulence. Chinese philosophy perspective provides a pragmatic approach and toolkits to cope with a fast-changing and uncertain environment by integrating traditional Chinese philosophical intelligence and modern 
management science techniques. This new perspective is expected to offer possible managerial inspirations for practitioners and decision makers when dealing with the business relationship between the organization and environment.

\section{References}

Aihie Osarenkhoe , (2010) " A coopetition strategy - a study of inter-firm dynamics between competition and cooperation", Business Strategy Series, Vol. 11 no. 6, pp. 343-362. http://dx.doi.org/10.1108/17515631011093052

Ang, S.-H. (2008), “Competitive intensity and collaboration: impact on firm growth across technological environments”, Strategic Management Journal, Vol. 29, pp. 1057-75. http://dx.doi.org/10.1002/smj.695

Bruton, G.D. and Lau, C.M. (2008), “Asian management research: status today and future outlook”, Journal of Management Studies, Vol. 45 No. 3, pp. 636-59, http://dx.doi.org/10.1111/j.1467-6486.2007.00758.x

Joseph Leu.(2006) " Social Networks in Silicon Valley ", Software Engineering ,no.2, pp.119-121

Mitsuru Kodama, (2005) "Innovation through networked strategic communities: case study on NTT DoCoMo", Journal of Management Development, Vol. 24 Iss: 2, pp.169 - 187, http://dx.doi.org/10.1108/02621710510579527

Peter Skarzynski, Doug Schaedler, (2010) "A new model for unlocking the value of entrepreneurial businesses", Business Strategy Series, Vol. 11 Iss: 5, pp.271 - 276, http://dx.doi.org/10.1108/17515631011080678

Sheh Seow Wah, (2010) "Confucianism and Chinese leadership", Chinese Management Studies, Vol. 4 Iss: 3, pp.280 285, http://dx.doi.org/10.1108/17506141011074165

Thomas H. Kang , (1997) Confucius and Confucianism: Questions and Answers

Youmin Xi, Xuanwei Cao, Liuxu Xiangli, (2010) "A Chinese view on rebuilding the integrity of management research: The evolving He-Xie management theory", Chinese Management Studies, Vol. 4 Iss: 3, pp.197 - 211, http://dx.doi.org/10.1108/17506141011074101 